\title{
Overexpression of MMP13 Is Associated with Clinical Outcomes and Poor Prognosis in Oral Squamous Cell Carcinoma
}

\author{
Vui King Vincent-Chong, ${ }^{1,2}$ Iman Salahshourifar, ${ }^{1}$ Lee Peng Karen-Ng, ${ }^{1}$ \\ Ming Yhong Siow, ${ }^{1}$ Thomas George Kallarakkal,, ${ }^{1,2}$ Anand Ramanathan,, ${ }^{1,2}$ Yi-Hsin Yang, ${ }^{3}$ \\ Goot Heah Khor, ${ }^{4}$ Zainal Ariff Abdul Rahman, ${ }^{1,2}$ Siti Mazlipah Ismail,, ${ }^{1,2}$ \\ Narayanan Prepageran, ${ }^{1,5}$ Wan Mahadzir Wan Mustafa, ${ }^{1,6}$ Mannil Thomas Abraham, ${ }^{1,7}$ \\ Keng Kiong Tay, ${ }^{1,8}$ Sok Ching Cheong, ${ }^{2,9}$ and Rosnah Binti Zain ${ }^{1,2}$ \\ ${ }^{1}$ Oral Cancer Research and Coordinating Centre, Faculty of Dentistry, University of Malaya, 50603 Kuala Lumpur, Malaysia \\ ${ }^{2}$ Department of Oro-Maxillofacial Surgical and Medical Sciences, Faculty of Dentistry, University of Malaya, \\ 50603 Kuala Lumpur, Malaysia \\ ${ }^{3}$ School of Pharmacy, Kaohsiung Medical University, Kaohsiung 807, Taiwan \\ ${ }^{4}$ Centre of Preclinical Science Studies, Faculty of Dentistry, Universiti Teknologi MARA, 40450 Shah Alam, \\ Selangor Darul Ehsan, Malaysia \\ ${ }^{5}$ Department of Otorhinolaryngology, Faculty of Medicine, University of Malaya, 50603 Kuala Lumpur, Malaysia \\ ${ }^{6}$ Department of Oral and Maxillofacial Surgery, Hospital Kuala Lumpur, 50300 Kuala Lumpur, Malaysia \\ ${ }^{7}$ Department of Oral and Maxillofacial Surgery, Hospital Tengku Ampuan Rahimah, 41586 Klang, Malaysia \\ ${ }^{8}$ Department of Oral Surgery, Hospital Umum Kuching, 93586 Kuching, Sarawak, Malaysia \\ ${ }^{9}$ Oral Cancer Research Team, Cancer Research Initiatives Foundation, 47500 Selangor Darul Ehsan, Malaysia
}

Correspondence should be addressed to Rosnah Binti Zain; rosnahbz12@yahoo.com

Received 20 June 2014; Revised 22 August 2014; Accepted 8 September 2014; Published 23 October 2014

Academic Editor: Steffen Maune

Copyright (C) 2014 Vui King Vincent-Chong et al. This is an open access article distributed under the Creative Commons Attribution License, which permits unrestricted use, distribution, and reproduction in any medium, provided the original work is properly cited.

\begin{abstract}
Matrix metalloproteinase 13 (MMP13) plays a central role in the MMP activation cascade that enables degradation of the extracellular matrix and basement membranes, and it is identified as a potential driver in oral carcinogenesis. Therefore, this study aims to determine the copy number, mRNA, and protein expression of MMP13 in oral squamous cell carcinoma (OSCC) and to associate these expressions with clinicopathological parameters. Copy number, mRNA, and protein expression analysis of $M M P 13$ were determined using real-time quantitative PCR and immunohistochemistry methods in OSCC samples. The correlations between MMP13 expressions and clinicopathological parameters were evaluated, and the significance of MMP13 as a prognostic factor was determined. Despite discrepancies between gene amplification and mRNA and protein overexpression rates, OSCC cases showed high amplification of MMP13 and overexpression of $M M P 13$ at both mRNA and protein levels. High level of MMP13 protein expression showed a significant correlation with lymph node metastasis $(P=0.011)$ and tumor staging $(P=0.002)$. Multivariate Cox regression model analysis revealed that high level of mRNA and protein expression of MMP13 were significantly associated with poor prognosis $(P<0.050)$. Taken together, these observations indicate that the MMP13 protein overexpression could be considered as a prognostic marker of OSCC.
\end{abstract}

\section{Introduction}

Oral cavity cancer is ranked as the sixth most common cancer worldwide, more than $90 \%$ of it being oral squamous cell carcinoma (OSCC) [1, 2]. Despite advances in diagnosis and treatment the survival rate still remains dismally low $[3,4]$. Increased mortality rate could be attributed to late diagnosis and lack of specific biomarkers to predict tumor progression 
and prognosis of the patients $[5,6]$. Hence, identifying specific biomarkers would pave the way for early detection and prognosis of OSCC.

We have recently detected several genomic copy number changes among OSCC cases [7]. Amplification at 11q23.3q25 was found in 57\% of OSCCs. The 11q22.2 region harbors a cluster of matrix metalloproteinases (MMPs) genes that play a pivotal role in tumor invasion and metastasis by degrading the extracellular matrix (ECM) [8]. The oncogenic role of MMP genes has been implicated in tumorigenesis and has widely been studied as potential biomarkers in various cancers, including OSCC [9]. Of these, overexpression of $M M P 13$ which is a collagenase appeared to be contributing to tumor cell invasion, metastasis, and poor prognosis [10]. Overexpression of this gene has been documented in numerous metastatic tumors such as head and neck SCC [11-13], vulvar SCC [14], laryngeal SCC [15], esophageal SCC [16], gastric cancer [17], malignant melanoma [18], bladder carcinoma [19], chondrosarcoma [20], colorectal carcinoma [21], breast carcinomas [22], and papillary thyroid carcinoma [23]. Product of MMP13 digests collagen and other extracellular components; hence its overexpression could contribute in tumorigenesis via uncontrolled degradation of extracellular matrix components and basement membranes [10].

Based on our previous study [7], we hypothesized that amplification at 11q22.2 might be the possible explanation of MMP13 overexpression and its tumorigenic role in OSCC. Multiple studies have reported overexpression of $M M P 13$ in head and neck SCC (HNSCC) [11-13, 24-26]. However there is paucity in research regarding the clinical outcomes of $M M P 13$ protein expression and its prognostic value in OSCC due to greater heterogeneity and aggressive features of OSCC as compared to other subsets of HNSCC [3, 27]. Hence, we further explored this gene at DNA, mRNA, and protein levels on independent samples to elucidate its potential role in tumorigenesis of OSCC and its correlation with clinical and survival characteristics in OSCC patients.

\section{Materials and Methods}

2.1. Samples Selection. We recruited 44, 68, and 103 independent OSCC samples for evaluation of DNA copy number, mRNA, and protein expression of MMP13 gene, respectively. Forty-four DNA samples extracted from snap-frozen OSCC tissues were used for copy number analysis. Sections were stained using hematoxylin and eosin (H\&E) and tumor cell percentage was gauged under microscope by two oral pathologists. In addition, cDNA of 68 OSCC and three normal mucosal samples were included for quantitation of the mRNA expression using real-time PCR. There were 21 OSCC samples overlapped between both copy number and mRNA expression analysis, 25 OSCC samples overlapped between both mRNA expression analysis and protein expression analysis, and 18 OSCC samples overlapped between both copy number analysis and protein expression analysis.

Immunohistochemical (IHC) analysis was performed on formalin fixed paraffin embedded (FFPE) tissues and frozen tissue sections. The FFPE tissues included 20 oral dysplastic lesions (ODLs), 5 normal oral mucosal tissues and 77 OSCC samples. The frozen tissue sections consisted of 26 OSCC samples. The FFPE samples were obtained from the archives of Oral Pathology Diagnostic and Research laboratory at the University of Malaya. The OSCC tissue specimens were derived from the tongue (excluding the base of the tongue), buccal mucosa, gum, palate, floor of mouth, and lip (C0006). All the tumor tissues were surgical excision specimens. The normal samples were obtained from normal oral mucosa adjacent to impacted wisdom teeth during surgical removal of the impacted teeth. All the frozen tissues were immediately snapped frozen in liquid nitrogen. Frozen tissue samples and sociodemographic and clinicopathologic data of OSCC samples were obtained from the Malaysian Oral Cancer Database and Tumor Bank System (MOCDTBS) managed by the Oral Cancer Research and Coordinating Centre, University of Malaya (OCRCC, UM) [28]. The American Joint Committee on cancer staging criteria was used for tumor staging [29]. All OSCC patients recruited in this study were treated based on pTNM staging that included surgery alone and a combination of surgery with radiotherapy and surgery with radiotherapy and chemotherapy. Written informed consent was obtained before sample collection. The specimens were collected, stored, and used later for this study. This study was approved by Medical Ethics Committee, Faculty of Dentistry, University of Malaya [MEC number DFOP1108/0083(L)].

\subsection{Copy Number Analysis by the TaqMan PCR Assay. DNA} was extracted from normal samples/tumor tissues with $\geq 70 \%$ tumor cell content using DNEasy Blood \& Tissue kit (Qiagen, Hilden, Germany) according to manufacturers' protocol. Copy number analysis was performed on 44 OSCCs according to the manufacturer's protocol as previously described [7]. Briefly, each gDNA was analyzed in quadruplicate by duplex TaqMan real-time polymerase chain reaction assays. The gDNA from 2 healthy volunteers (female and male) and 2 normal oral mucosa tissues served as calibrator controls. Copy number analysis was done using MMP13 TaqMan Copy Number Assay (Hs01829774_cn) (Applied Biosystems, Foster City, CA, USA). PCR was done in a total volume of $20 \mu \mathrm{L}$ consisting of $4 \mu \mathrm{L}$ of genomic DNA $(5 \mathrm{ng} / \mu \mathrm{L}), 10 \mu \mathrm{L}$ of $2 \mathrm{x}$ TaqMan Genotyping Master Mix (Applied Biosystems, Foster City, CA, USA), $1 \mu \mathrm{L}$ of 20x TaqMan Copy number assay, $1 \mu \mathrm{L}$ of 20x TaqMan copy number reference assay (RNAse P), and $4 \mu \mathrm{L}$ of nuclease free water. Quantitative PCR was performed on an ABI 7500 Fast Real Time PCR System (Applied Biosystems, Foster City, CA, USA) using the manufacturer's PCR conditions as follows: initial denaturation at $95^{\circ} \mathrm{C}$ for 10 minutes followed by 40 cycles of denaturation for 15 seconds at $95^{\circ} \mathrm{C}$ and annealing for 60 seconds at $60^{\circ} \mathrm{C}$.

The values of copy number for each sample were normalized using RNAase $\mathrm{P}$ as a reference control with 2 copies in the human genome. Copy number was quantified using the equation $2 \times(2-\Delta \Delta \mathrm{CT})$, comparative $\mathrm{CT}(\Delta \Delta \mathrm{CT})$ relative quantitation method [30]. Target and reference assays that were used for copy number calculation were derived from the mean of quadruplicate, RNase P, and the calibrator samples. The calculated relative quantity was multiplied by a base copy 
number of 2 to obtain the copy number value. The values less than one and more than 2.5 were considered as deletion and amplification, respectively [31].

2.3. mRNA Expression of MMP13 Using qRT-PCR. RNA extraction was done on normal samples/tumor tissues with $\geq 70 \%$ tumor cell content using RNeasy Micro kit (Qiagen, Hilden, Germany) according to manufacturers' protocol. The integrity of RNA was tested using Agilent Bioanalyzer-2100 (Agilent, Palo Alto, CA, USA). Reverse transcription of total RNA was done using High Capacity cDNA reverse transcription kit (Applied Biosystems, Foster City, CA, USA). The cDNA of each sample was obtained in triplicate and the gene expression of MMP13 was performed using 7500 Fast Real-Time PCR System (Applied Biosystems, Foster City, CA, USA). TaqMan Gene Expression Assay was carried out for MMP13 (Hs00233992_ml) according to the manufacturer's protocol (Applied Biosystems, Foster City, CA, USA). The relative quantification/fold change (RQ) was calculated based on the $2-\Delta \Delta C T$ method using 7500 Fast System SDS Software 1.3.1 (Applied Biosystems, Foster City, CA, USA). The GAPDH gene was used as endogenous control and the cDNA from normal oral mucosa tissues $(\mathrm{RQ}=1)$ was utilized for normalization of test samples.

\section{Tissue Microarray}

Tissue microarray (TMA) of $1.0 \mathrm{~mm}$ core size was constructed as described previously [32] using a semiautomatic Tissue Arrayer Minicore (Alphelys, SAS, France). All 77 OSCC FFPE blocks and the respective $5 \mu \mathrm{m}$ H\&E stained slides were selected to identify and mark out the representative tumor areas by 2 oral pathologists independently. Approximately, 3-6 cores from the selected areas of donor blocks were transferred to the recipient paraffin blocks. The completed recipient paraffin blocks also known as TMA were incubated overnight at $37^{\circ} \mathrm{C}$ and $4 \mu$ thick sections were sectioned on poly-lysine slides.

3.1. Immunohistochemistry and Scoring System. IHC was performed on $4 \mu \mathrm{m}$ thick FFPE sections using the Envision technique, Dako Real EnVision Detection System and Peroxidase/DAB+ (Dako Corporation, Carpinteria, CA, USA) according to the manufacturer's protocol. Briefly, FFPE sections were deparaffinized in Xylene and rehydrated in ethanol series. Antigen retrieval was carried out using an electric pressure cooker $\left(110^{\circ} \mathrm{C}, 20\right.$ minutes) in $10 \mathrm{mM}$ citrate buffer ( $\mathrm{pH}$ 6.0). The sections were immersed in blocking solution (Dako Corporation, Carpinteria, CA, USA) for $10 \mathrm{~min}$ at room temperature followed by washing with Phosphatebuffered saline ( $\mathrm{pH}$ 7.4) plus $0.1 \%$ Tween 20 for blocking the endogenous peroxidase activity. The sections were then incubated with $8 \mu \mathrm{g} / \mathrm{mL}$ of monoclonal anti-MMP13 (MAB511, R\&D Systems, Inc, Heidelberg, Germany) overnight at $4^{\circ} \mathrm{C}$ for FFPE sectioned and one hour at room temperature for frozen tissue sectioned. After washing with PBS buffer, sections were incubated with the peroxidase labeled secondary antibody from the Envision kit for 45 minutes for the immunoreactivity performances. Finally, sections were stained with $3^{\prime} 3$ diaminobenzidine substrate chromogen (Dako Corporation, Carpinteria, CA, USA), counterstained with Mayer's hematoxylin, dehydrated, and mounted.

Digitalized immunostained TMA spots were analyzed and scored by 2 oral pathologists independently based on semiquantitative scoring system using TMA software module 1.15.2 (3DHISTECH, Budapest, Hungary). The intensity scores were quantified using the following scores: negative $=$ 0 ; weak $=1 ;$ moderate $=2$; and strong $=3$. The proportion of immunopositive cells was quantified as follows: $0=$ negative; $1=<10 \% ; 2=11-50 \% ; 3=51-80 \%$; and $4=\geq 80 \%$ of positive cells. The final immunoreactive score was determined by multiplying the intensity and the proportion scores of the stained cells to obtain an immunoreactive score ranging from 0 to $12[33,34]$. Cores with discrepant scores were discussed by both pathologists to achieve a consensus to derive the final score. The mean of consolidated immunoreactive scores for each case was recorded.

3.2. Selection of Cutoff Score for MMP13 Protein Expression. The clinicopathological parameters were first dichotomized as follows: lymph node metastasis (no versus yes), tumor staging (early versus advanced), tumor sizes ( $\mathrm{T} 1$ and $\mathrm{T} 2$ versus T3 and T4), and survival status (alive versus dead). Receiver operating characteristic (ROC) curve analysis was used to determine the best cutoff score for $M M P 13$ protein expression to each of dichotomized clinicopathological parameters using 0, 1 criterion [35]. For MMP13 immunoreactive scoring, the sensitivity and specificity of each score were plotted to generate various ROC curves. The score which was closest to the point with maximum sensitivity and specificity was selected as the cutoff value. The immunoreactive scores were divided into high and low MMP13 expression where low expression was the scores below or equal to the cutoff value, while high expression was the scores above the cutoff value.

3.3. Statistical Analysis. Copy number alterations, mRNA, and protein expression level of MMP13 were compared between tumor and normal tissues using the Mann-Whitney $U$ test. The copy number of MMP13 was classified into two groups, amplification ( $>2.5$ copies) and nonamplification ( $\leq 2.5$ copies). Gene expression of $M M P 13$ was classified into two groups, high and low, with a cutoff value based on the 75th percentile of the respective relative quantitative (RQ) values. A receiver operating characteristics (ROC) curve was used to determine the best cut-off point based on the immunoreactive scores of the MMP13 for specificity and sensitivity. Correlation between copy number and gene expression levels of MMP13 was assessed via Spearman correlation analysis. Associations between the copy number, mRNA, and protein expression of MMP13 and the clinicopathological parameters were analyzed by chi square test (or Fisher exact test where appropriate). Survival curves were plotted and compared by the log rank tests using the Kaplan-Meier analysis. In addition, Cox regression analysis was conducted to evaluate the MMP13 expression as an independent prognostic factor. All statistical analyses were 
TABLE 1: Area under the receiver operating characteristic curve (AUC) for each clinicopathological feature.

\begin{tabular}{lcc}
\hline Clinicopathological parameters & AUC (95\% CI) & $P$ value \\
\hline Lymph node metastasis (yes versus no) & $0.565(0.453-0.677)$ & 0.264 \\
Tumor staging (advanced versus early) & $0.606(0.486-0.725)$ & 0.076 \\
Tumor sizes (T1 and T2 versus T3 and T4) & $0.552(0.439-0.664)$ & 0.378 \\
Survival (death versus alive) & $0.525(0.409-0.642)$ & 0.658 \\
\hline
\end{tabular}

performed using the SPSS statistical package (SPSS version 12.0, Chicago, IL, USA) and the $P$ value $<0.05$ was considered significant.

\section{Results}

4.1. Definition of Cutoff Score for MMP13 Protein Expression in OSCC. ROC curve analysis was performed based on the results of IHC evaluation. Results showed that ROC curve analysis for tumor staging has the shortest distance from the curve to the point $(0.0,1.0)$ (Table 1; Figure 1). Hence, cutoff value for tumor staging was selected. The cutoff score for low $M M P 13$ expression was set to $<3.50$ and the counterpart as high MMP13 expression.

4.2. MMP13 Gene Copy Number, mRNA, and Protein Expression in OSCC. Amplification of MMP13 was identified in $59.1 \%$ of the OSCC samples (26 out of 44 ) with an average copy number of $3.09 \pm 1.81$ (Figure 2 ). In line with this the $M M P 13$ mRNA was found to be expressed at a high level in $95.59 \%$ of the OSCC samples (65 out of 68) with an average gene expression fold change of $\mathrm{RQ}=276.28$ (Figure 3 ). Spearman's correlation coefficient showed a nonsignificant correlation between copy number and gene expression of MMP13 $\left(n=21, r^{2}=0.237, P=0.302\right)$, between copy number and protein expression of $M M P 13\left(n=18, r^{2}=0.125, P=\right.$ $0.621)$, and between gene expression and protein expression of $M M P 13\left(n=23, r^{2}=0.378, P=0.062\right)$.

In IHC analysis of MMP13 protein, the epithelial cells of normal oral mucosal tissues showed a negative staining. A weak to moderate staining was seen in the cytoplasm of the epithelial cells of the basal and spinous layers in dysplastic oral mucosa. More than $75 \%$ of OSCCs displayed a strong staining in the cytoplasm of epithelial tumor cells. All the normal, dysplastic, and OSCC tissue samples demonstrated moderate MMP13 immunostaining of the stromal compartment including the inflammatory cells. The expression of $M M P 13$ protein was statistically different between OSCC and normal oral mucosal tissues $(P<0.05)$ in contrast to OSCC and ODLs (Figure 4).

4.3. Association of MMP13 Gene Copy Number, mRNA, and Protein Expression with Clinicopathologic Parameters. Change in copy number of MMP13 gene was found to be statistically significant between OSCC and normal oral mucosal tissues $(P=0.002)$. However, there was no significant association between copy number alterations and clinicopathologic factors. Expression of MMP13 mRNA was significantly higher in OSCCs compared with normal oral mucosa samples $(P<0.005)$, but it had no significant association with clinicopathologic factors. In contrast, high expression of MMP13 protein was significantly correlated with lymph node metastasis $(P=0.011)$, tumor staging (0.002), and a trend towards association with tumor sizes (T3 and T4, $P=0.063$ ) (Table 2).

4.4. Significance of MMP13 Gene Copy Number, $m R N A$, and Protein Expression as Prognostic Indicators. The followup time for patients that were recruited for copy number analysis of MMP13 ranged from 2 to 88 months (mean: 26.73 months, median: 24.5 months). Two-year survival rates for low and high copy number of $M M P 13$ were $70.0 \%$ and $55.19 \%$, respectively. Results of Kaplan-Meier analysis showed no significant association between MMP13 amplification and poor prognosis $(P=0.479)$ (Figure 5).

The follow-up time for patients that were used for analysis of MMP13 mRNA expression ranged from 1 month to 52 months (mean: 17.71 months, median: 13.0 months). Three-year survival rates for low and high expression of $M M P 13$ were $57.76 \%$ and $17.45 \%$, respectively. The $M M P 13$ mRNA expression showed significant correlation with poor prognosis $(P=0.016)$ in Kaplan-Meier analysis (Figure 5). In multivariate Cox regression analysis, the expression of MMP13 mRNA remained as a significant prognostic factor for survival after adjustment for age, gender, risk habits, and clinicopathologic parameters (tumor sites, lymph node metastasis, and tumor staging) which are the common confounding factors in OSCC (HRR $=2.23$, 95\% CI $1.015-$ 4.896, $P=0.046$ ) (Table 3).

For MMP13 protein expression, the follow-up time for patients ranged from 1 month to 92 months (mean: 29.13 months, median: 20.5 months). Three-year survival rate for the high and low expression of $M M P 13$ protein was $34.73 \%$ and $72.38 \%$, respectively. Results of the five-year survival rate analysis demonstrated a significant association between positive $M M P 13$ protein expression and poor prognosis $(P=$ 0.005) (Figure 5).

After adjustment for selected sociodemographic (age, gender, and risk habits) and clinicopathological parameters (tumor subsite, tumor differentiation, and pattern of invasion), positive $M M P 13$ expression remained a significant prognostic factor for overall survival of OSCC $(\mathrm{HRR}=3.850$, 95\% CI 1.234-12.010, $P=0.020$, data not shown). Positive MMP13 expression showed a considerable trend as an independent prognostic factor towards unfavorable overall survival after adjustment with other clinicopathological parameters such as tumor subsites, lymph node metastasis, tumor staging, pattern of invasion, and tumor differentiation $(\mathrm{HRR}=2.84,95 \%$ CI $0.922-8.768, P=0.069)$ (Table 4$)$. 

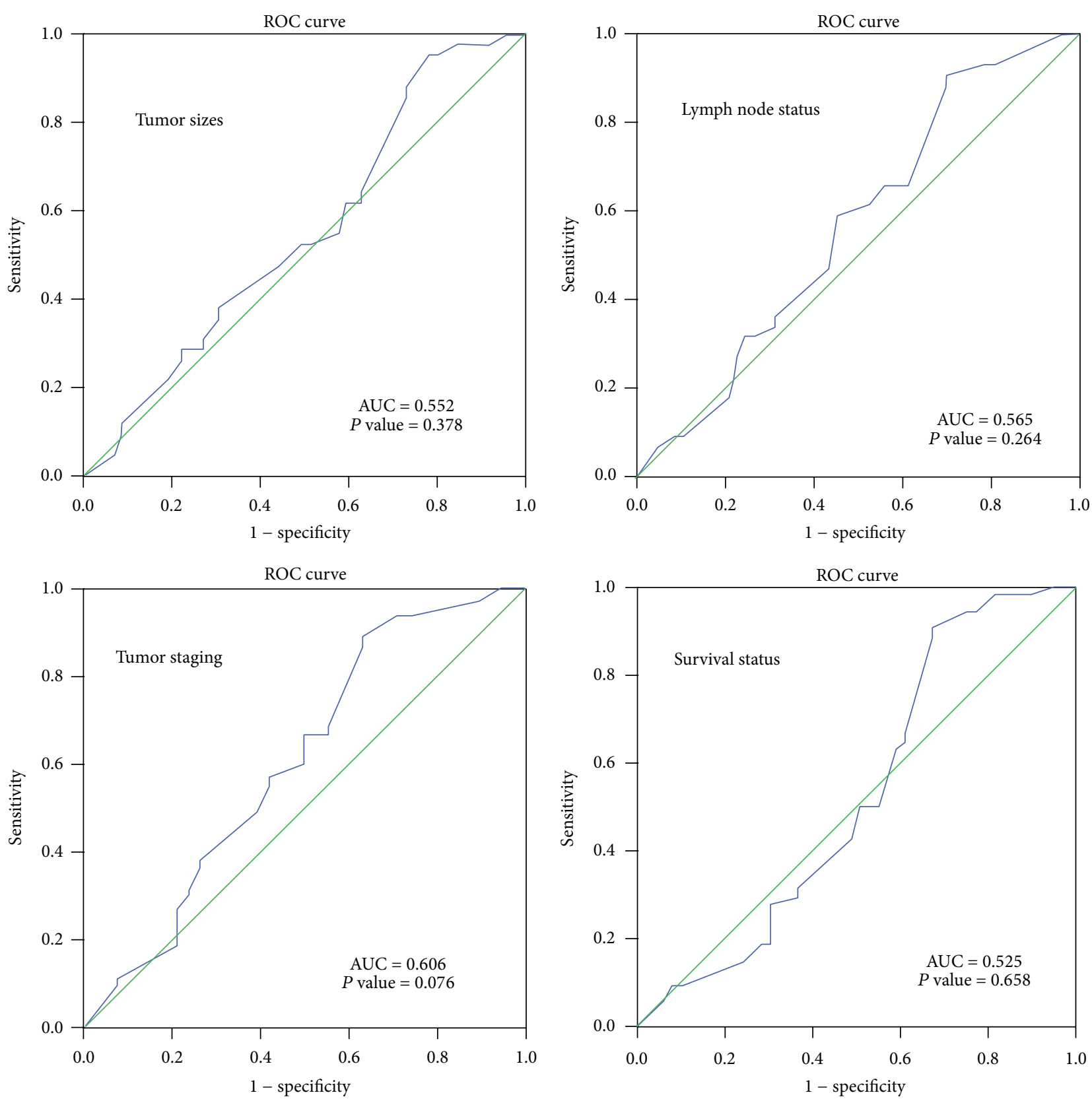

FIGURE 1: Determination the cutoff value of MMP13 expression in OSCC by receiver operating characteristic (ROC) curves. The clinicopathological parameters including lymph node metastasis, tumor staging, tumor sizes and survival status, the sensitivity, and $1-$ specificity were plotted. The areas under curve (AUC) and the $P$ value were indicated.

\section{Discussion}

Despite several studies that have demonstrated the overexpression of MMP13 mRNA and protein expression among OSCCs and head and neck SCCs [11-13, 24-26, 36-38], the reason for overexpression and its role in pathogenesis of OSCC remained unanswered. Copy number alterations are widely accepted as one of the major drivers in cancer mainly by altering the gene expression levels [39]. Amplification in 11q22.2 which harbors the MMP genes was a frequent finding in our previous study [7]. Hence, we postulated that the pathogenic role of $M M P 13$ overexpression could be linked to copy number changes at this region. Therefore, the role of this gene in pathogenesis of OSCC was explored using independent set of samples at DNA, mRNA, and protein levels as independent set of samples would draw a stronger conclusion for biomarker discovery in cancer [40]. In line with our previous study [7], amplification of MMP13 gene was common and was found in 59.1 of cases while overexpression at both mRNA and protein levels was more frequent and found in $95.6 \%$ and $79.6 \%$ of patients, respectively. Consistent changes at DNA, mRNA, and protein levels of $M M P 13$ on independent set of 


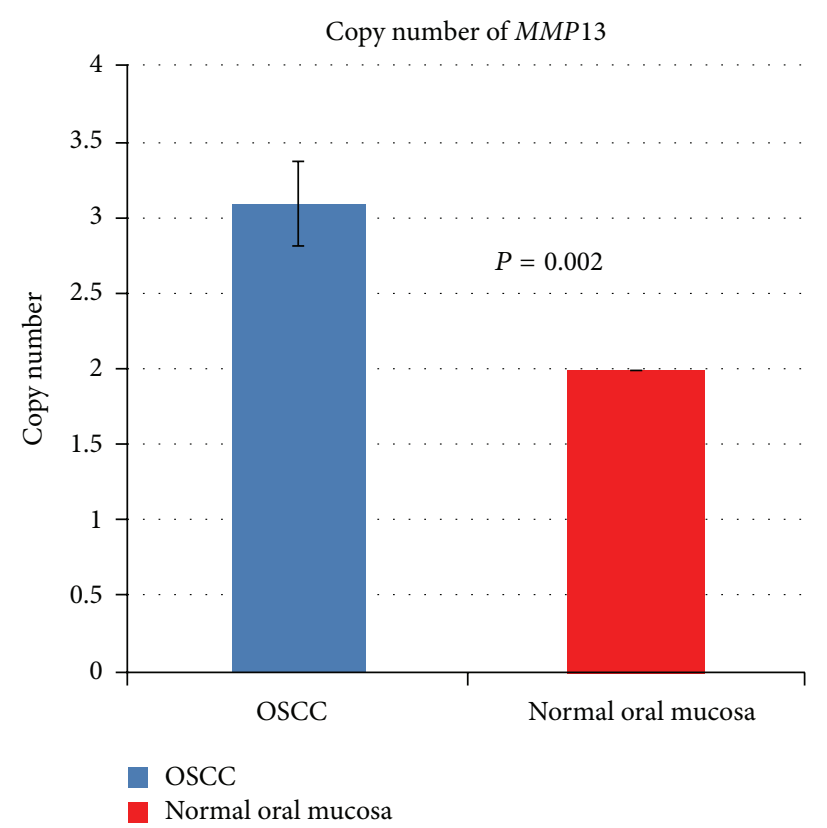

FIgURE 2: Copy number alterations of MMP13 between OSCC and normal oral mucosa. The copy number alterations of MMP13 between OSCC and normal oral mucosa tissues were statistically different $(P=0.002)$ with an average of 3.09 copies. The copy number for normal oral mucosa (NT) of MMP13 was 2 due to presentation as two diploid copies as reference control.

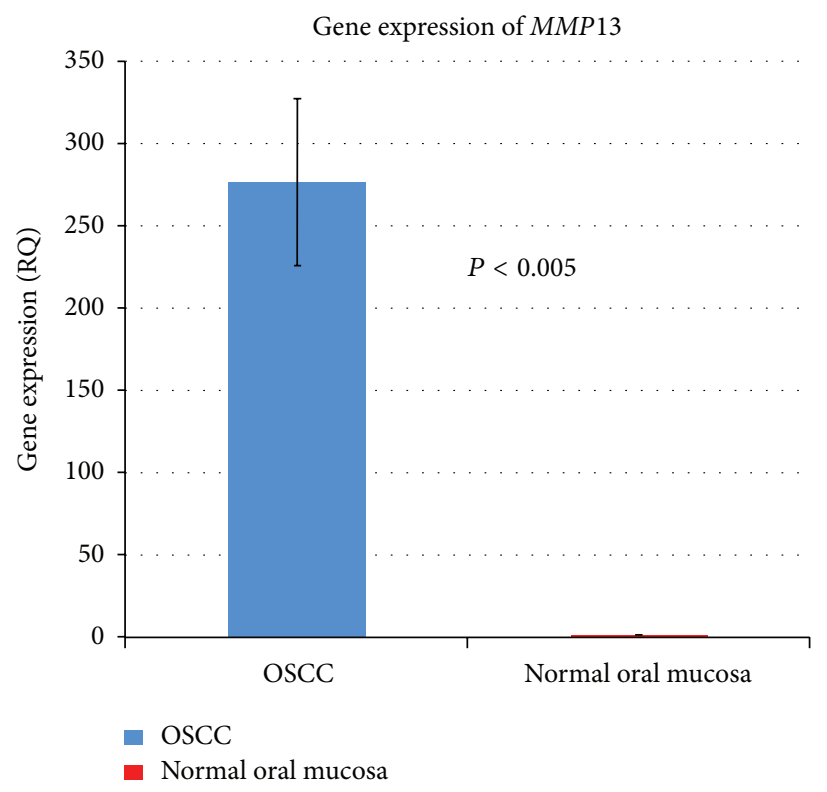

Figure 3: The gene expression level (RQ) of MMP13 in OSCC samples based on the fold change expressed as an average of 68 OSCC samples. Expression level of MMP13 was RQ $=276.28$ while the gene expression between OSCC and normal mucosa was statistically different $(P<$ 0.005). The RQ for normal tissue (NT) of MMP13 was 1 due to the normalization.

samples reflect that gene amplification could be one of the possible mechanisms for MMP13 overexpression. However, gene amplification may increase gene expression at both mRNA and protein levels but concurrent changes in mRNA and protein levels do not correlate in most of the cases mainly due to the regulatory controls at different levels [41]. Hence, a trend of correlation would be expected and only a small percentage of transcriptional changes would correspond to similar protein expression changes. Thus, investigation of mRNA and protein expression even on the same samples may not guarantee a statistical correlation between these events as seen in Yamamoto et al. [41]. In the current study, similar trend of overexpression at different levels on independent set of samples could be considered as a positive correlation 


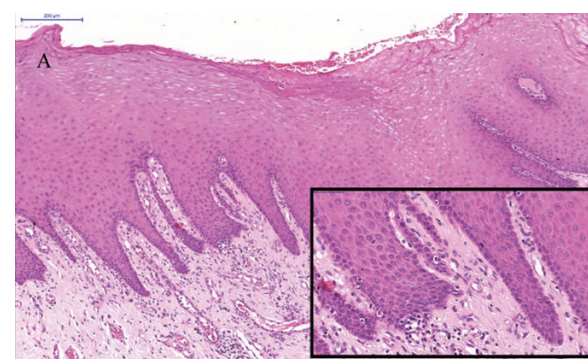

(a)

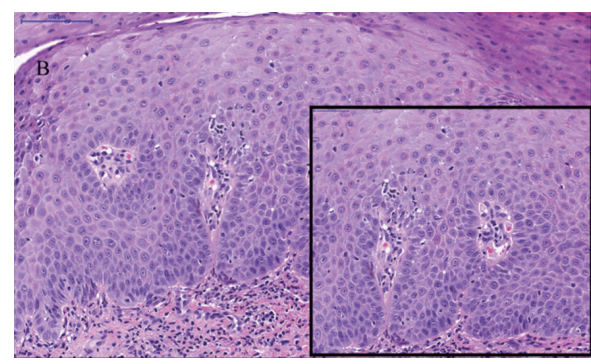

(b)

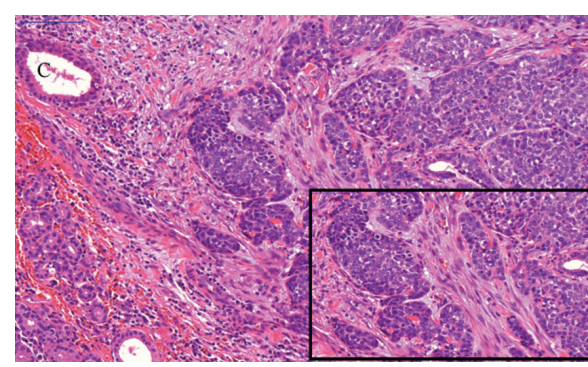

(c)

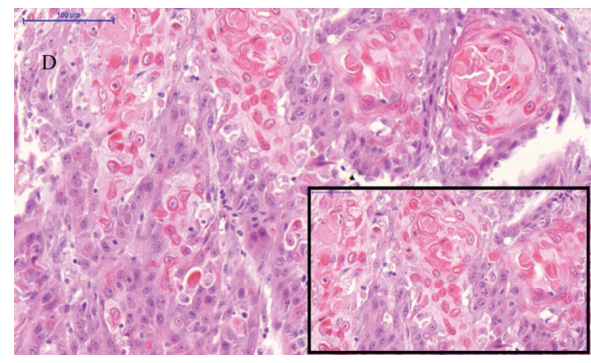

(d)

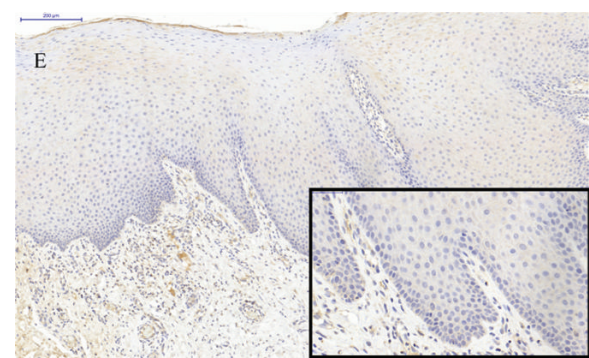

(e)

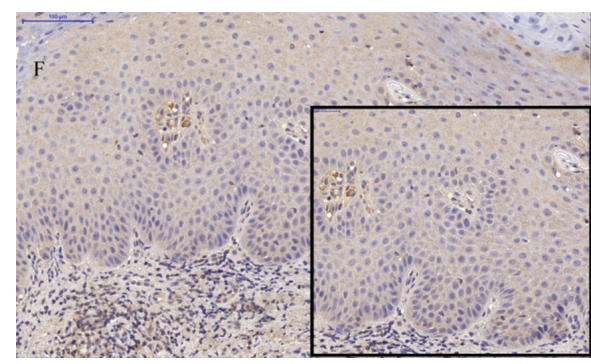

(f)

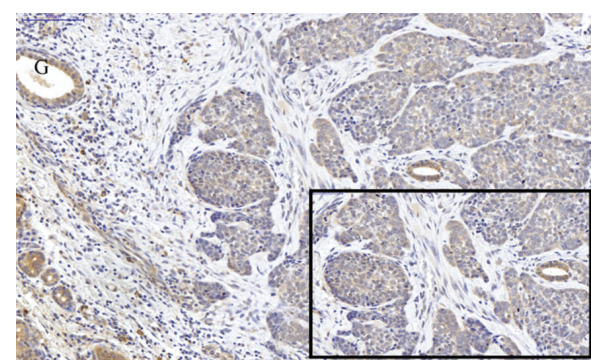

(g)

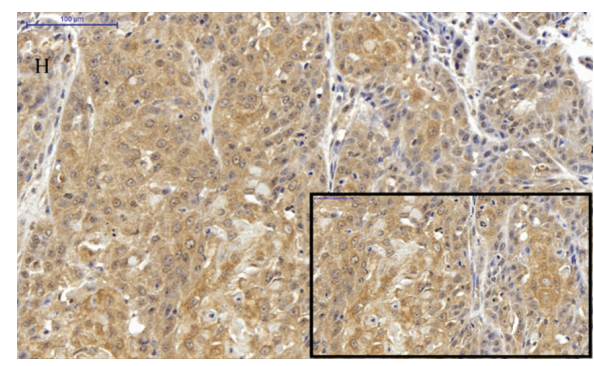

(h)

FIGURE 4: Immunohistochemistry of MMP13. Normal oral mucosa (a) H\&E stain (magnification 400x and 1600x); (e) anti-MMP13 antibody immunostain was negative in the normal oral mucosa (magnification 400x and 1600x). Dysplastic oral tissue (b) H\&E stain (magnification 800x and 1600x); (f) anti-MMP13 antibody showed weak to moderate immunostaining in the cytoplasm of the dysplastic epithelial cells (magnification 800x and 1600x). OSCC (c and d) H\&E stained (magnification 800x and 1600x); (g) anti-MMP13 antibody immunostaining showed low expression and (h) high expression in the cytoplasm of the epithelial tumor cells (magnification 800x and 1600x). All the oral tissues showed moderate anti-MMP13 antibody immunostaining of the stroma and inflammatory cells in the microenvironment.

despite insignificant statistical correlation. In other words, identifying overexpression of $M M P 13$ mRNA in a high percentage of patients reflects that MMP13 protein could be an appropriate potential biomarker for further analysis among OSCCs as a trend toward significant correlation was found between mRNA and protein expression $(r=0.378$, $P=0.062)$.

MMP13 protein was highly expressed in epithelial cells of OSCCs as compared to normal oral mucosal epithelial cells.
This was in concordance with the statistical difference that was found in copy number changes at DNA level between OSCCs and normal mucosa. Therefore, overexpression of MMP13 could be the consequence of amplification. In addition, increased expression of $M M P 13$ protein from epithelial cells of normal mucosa as compared to OSCC reflects the important role of this gene in progression to OSCC. Our results were consistent with the previously reported evidence that was conducted on ODLs and OSCCs [36]. Hence, 
TABLE 2: Association of $M M P 13$ protein expression with clinicopathological parameters.

\begin{tabular}{|c|c|c|c|c|c|}
\hline \multirow{2}{*}{ Variables } & \multirow{2}{*}{ Category } & \multirow{2}{*}{ Number of patients (\%) } & \multicolumn{2}{|c|}{$M M P 13$ expression $(n, \%)$} & \multirow{2}{*}{$P$ value } \\
\hline & & & Low level of expression & High level of expression & \\
\hline & & 103 & $21(20.4)$ & $82(79.6)$ & \\
\hline \multicolumn{6}{|l|}{ Total } \\
\hline \multirow{2}{*}{ Gender } & Male & $35(34.0)$ & $10(28.6)$ & $25(71.4)$ & \multirow{2}{*}{0.139} \\
\hline & Female & $68(66.0)$ & $11(16.2)$ & $57(83.8)$ & \\
\hline \multirow{2}{*}{ Age (years) } & $<45$ & $11(10.7)$ & $3(27.3)$ & $8(72.7)$ & \multirow{2}{*}{0.691} \\
\hline & $\geq 45$ & $92(89.3)$ & $18(19.6)$ & $74(80.4)$ & \\
\hline \multirow{2}{*}{ Smoking } & No & $81(78.6)$ & $15(18.5)$ & $66(81.5)$ & \multirow{2}{*}{0.380} \\
\hline & Yes & $22(21.4)$ & $6(27.3)$ & $16(72.7)$ & \\
\hline \multirow{2}{*}{ Drinking } & No & $71(68.9)$ & $13(18.3)$ & $58(81.7)$ & \multirow{2}{*}{0.435} \\
\hline & Yes & $32(31.1)$ & $8(25.0)$ & $24(75.0)$ & \\
\hline \multirow{2}{*}{ Betel quid chewing } & No & $49(47.6)$ & $10(20.4)$ & $39(79.6)$ & \multirow{2}{*}{0.996} \\
\hline & Yes & $54(52.4)$ & $11(20.4)$ & $43(79.6)$ & \\
\hline \multirow{2}{*}{ Tumor site } & Non-tongue ${ }^{*}$ & $68(66.0)$ & $14(20.6)$ & $54(79.4)$ & \multirow{2}{*}{0.944} \\
\hline & Tongue & $35(34.0)$ & $7(20.0)$ & $28(80.0)$ & \\
\hline \multirow{2}{*}{ Tumor size ${ }^{* *}$} & T1-T2 & $59(58.4)$ & $16(27.1)$ & $43(72.9)$ & \multirow{2}{*}{0.063} \\
\hline & T3-T4 & $42(41.6)$ & $5(11.9)$ & $37(88.1)$ & \\
\hline \multirow{2}{*}{ Lymph node metastasis ${ }^{* *}$} & Negative & $57(56.4)$ & $17(29.8)$ & $10(70.2)$ & \multirow{2}{*}{0.011} \\
\hline & Positive & $44(43.6)$ & $4(9.1)$ & $40(90.9)$ & \\
\hline \multirow{2}{*}{ pTNM staging $^{* *}$} & Early stage & $38(37.6)$ & $14(36.8)$ & $24(63.2)$ & \multirow{2}{*}{0.002} \\
\hline & Advanced stage & $63(62.4)$ & 7 (11.1) & $56(88.9)$ & \\
\hline \multirow{2}{*}{ Pattern of invasion ${ }^{* *}$} & Cohesive & $13(15.5)$ & $5(38.5)$ & $8(61.5)$ & \multirow{2}{*}{0.140} \\
\hline & Non-cohesive & $71(84.5)$ & $13(18.3)$ & $58(81.7)$ & \\
\hline \multirow{2}{*}{ Differentiation ${ }^{* *}$} & Well & $45(44.1)$ & $11(24.4)$ & $34(75.6)$ & \multirow{2}{*}{0.392} \\
\hline & Poor and Moderate & $57(55.9)$ & $10(17.5)$ & $47(82.5)$ & \\
\hline
\end{tabular}

${ }^{*}$ Buccal mucosa, gingiva, lip, floor of mouth, palate.

${ }^{* *}$ Data missing.

Significant $P$ values were highlighted in bold.

TABLE 3: Multivariate cox regression model analysis of MMP13 mRNA expression in OSCC overall survival.

\begin{tabular}{|c|c|c|c|c|c|}
\hline \multirow{2}{*}{ Variables } & \multirow{2}{*}{ Category } & \multirow{2}{*}{ Number of patients (\%) } & \multicolumn{3}{|c|}{ Multivariate Logistic regression ${ }^{* *}$} \\
\hline & & & OR & $95 \%$ CI & $P$ value \\
\hline Total & & 68 & & & \\
\hline \multirow{2}{*}{ mRNA expression of $M M P 13$} & Low & $50(73.5)$ & $1.00^{\dagger}$ & \multirow{2}{*}{$1.015-4.896$} & \multirow{2}{*}{0.046} \\
\hline & High & $18(26.5)$ & 2.23 & & \\
\hline \multirow{2}{*}{ Gender } & Male & $24(35.3)$ & $1.00^{\dagger}$ & \multirow{2}{*}{$0.388-2.806$} & \multirow{2}{*}{0.933} \\
\hline & Female & $44(64.7)$ & 1.043 & & \\
\hline \multirow{2}{*}{ Age (years) } & $<45$ & $12(17.6)$ & $1.00^{\dagger}$ & \multirow{2}{*}{$0.397-3.009$} & \multirow{2}{*}{0.864} \\
\hline & $\geq 45$ & $56(82.4)$ & 1.092 & & \\
\hline \multirow{2}{*}{ Smoking } & No & $44(64.7)$ & $1.00^{\dagger}$ & \multirow{2}{*}{$0.240-2.071$} & \multirow{2}{*}{0.524} \\
\hline & Yes & $24(35.3)$ & 0.704 & & \\
\hline \multirow{2}{*}{ Drinking } & No & $51(75.0)$ & $1.00^{\dagger}$ & \multirow{2}{*}{$0.391-2.341$} & \multirow{2}{*}{0.922} \\
\hline & Yes & $17(25.0)$ & 0.956 & & \\
\hline \multirow{2}{*}{ Betel quid chewing } & No & $40(58.8)$ & $1.00^{\dagger}$ & \multirow{2}{*}{$0.652-3.718$} & \multirow{2}{*}{0.319} \\
\hline & Yes & $28(41.2)$ & 1.557 & & \\
\hline \multirow{2}{*}{ Tumor site } & Non-tongue ${ }^{*}$ & $38(55.9)$ & $1.00^{\dagger}$ & \multirow{2}{*}{$0.516-2.933$} & \multirow{2}{*}{0.640} \\
\hline & Tongue & $30(44.1)$ & 1.230 & & \\
\hline \multirow{2}{*}{ Lymph node metastasis } & Negative & $33(48.5)$ & $1.00^{\dagger}$ & \multirow{2}{*}{$1.028-20.275$} & \multirow{2}{*}{0.046} \\
\hline & Positive & $35(51.5)$ & 4.565 & & \\
\hline \multirow{2}{*}{ pTNM Staging } & Early & $22(32.4)$ & $1.00^{\dagger}$ & \multirow{2}{*}{$0.339-13.469$} & \multirow{2}{*}{0.419} \\
\hline & Advanced & $46(67.6)$ & 2.137 & & \\
\hline
\end{tabular}

CI: confidence interval.

${ }^{*}$ Buccal mucosa, gingiva, lip, floor of mouth, palate.

${ }^{\dagger}$ Reference category.

Significant $P$ values were highlighted in bold.

** Multivariate logistic regression analysis was applied to adjust the confounders [age, gender, risk habits (cigarette smoking, betel quid chewing, and alcohol drinking)], and clinicopathologic parameters [tumor sites, lymph node metastasis, and pathological tumor staging]. 
TABLE 4: Multivariate cox regression model analysis of MMP13 protein expression in OSCC overall survival.

\begin{tabular}{|c|c|c|c|c|c|}
\hline \multirow{2}{*}{ Variables } & \multirow{2}{*}{ Category } & \multirow{2}{*}{ Number of patients (\%) } & \multicolumn{3}{|c|}{ Multivariate Logistic regression ${ }^{* *}$} \\
\hline & & & OR & $95 \%$ CI & $P$ value \\
\hline Total & & 103 & & & \\
\hline \multirow{2}{*}{ Protein expression of $M M P 13$} & Low & $21(20.4)$ & $1.00^{\dagger}$ & \multirow{2}{*}{$0.922-8.768$} & \multirow{2}{*}{0.069} \\
\hline & High & $82(79.6)$ & 2.84 & & \\
\hline \multirow{2}{*}{ Gender } & Male & $35(34.0)$ & $1.00^{\dagger}$ & \multirow{2}{*}{$0.366-2.530$} & \multirow{2}{*}{0.938} \\
\hline & Female & $68(66.0)$ & 0.96 & & \\
\hline \multirow{2}{*}{ Age (years) } & $<45$ & $11(10.7)$ & $1.00^{\dagger}$ & \multirow{2}{*}{$0.127-2.997$} & \multirow{2}{*}{0.548} \\
\hline & $\geq 45$ & $92(89.3)$ & 0.62 & & \\
\hline \multirow{2}{*}{ Smoking } & No & $81(78.6)$ & $1.00^{\dagger}$ & \multirow{2}{*}{$0.150-2.017$} & \multirow{2}{*}{0.367} \\
\hline & Yes & $22(21.4)$ & 0.55 & & \\
\hline \multirow{2}{*}{ Drinking } & No & $71(68.9)$ & $1.00^{\dagger}$ & \multirow{2}{*}{$0.376-1.656$} & \multirow{2}{*}{0.531} \\
\hline & Yes & $32(31.1)$ & 0.79 & & \\
\hline \multirow{2}{*}{ Betel quid chewing } & No & $49(47.6)$ & $1.00^{\dagger}$ & \multirow{2}{*}{$0.195-1.178$} & \multirow{2}{*}{0.109} \\
\hline & Yes & $54(52.4)$ & 0.48 & & \\
\hline \multirow{2}{*}{ Tumor site } & Non-tongue $^{*}$ & $68(66.0)$ & $1.00^{\dagger}$ & \multirow{2}{*}{$0.306-1.785$} & \multirow{2}{*}{0.502} \\
\hline & Tongue & $35(34.0)$ & 0.74 & & \\
\hline \multirow{2}{*}{ Lymph node metastasis ${ }^{* * *}$} & Negative & $57(56.4)$ & $1.00^{\dagger}$ & \multirow{2}{*}{$0.771-4.188$} & \multirow{2}{*}{0.175} \\
\hline & Positive & $44(43.6)$ & 1.80 & & \\
\hline \multirow{2}{*}{ pTNM staging $^{* * *}$} & Early & $38(37.6)$ & $1.00^{\dagger}$ & \multirow{2}{*}{$0.662-4.683$} & \multirow{2}{*}{0.257} \\
\hline & Advanced & $63(62.4)$ & 1.76 & & \\
\hline \multirow{2}{*}{ Pattern of invasion ${ }^{* * *}$} & Cohesive & $13(15.5)$ & $1.00^{\dagger}$ & \multirow{2}{*}{$0.839-10.374$} & \multirow{2}{*}{0.09} \\
\hline & Noncohesive & $71(84.5)$ & 2.95 & & \\
\hline Differentiation $* * *$ & Well & $45(44.1)$ & $1.00^{\dagger}$ & $0258-1009$ & 005 \\
\hline Dillerentiation & Moderate and poor & $57(55.9)$ & 0.51 & $0.258-1.009$ & 0.05 \\
\hline
\end{tabular}

CI: confidence interval.

${ }^{*}$ Buccal mucosa, gingiva, lip, floor of mouth, palate.

${ }^{\dagger}$ Reference category.

${ }^{* *}$ Multivariate logistic regression analysis was applied to adjust the confounders [age, gender, risk habits (cigarette smoking, betel quid chewing and alcohol drinking)] and clinico-parameters [tumor subsites, lymph node metastasis, tumor staging, pattern of invasion and pathological tumor differentiation].

*** Data missing.

MMP13 protein might be considered as a useful biomarker for ODLs with a risk of malignant transformation. However, the sample size of ODLs was small to draw a strong conclusion; hence further investigation will be needed.

Despite lack of significant association between copy number and mRNA expression of MMP13 with clinicopathologic parameters, overexpression of MMP13 mRNA was associated with poor prognosis and remained as an independent prognostic factor. Similar evidence has been reported on esophageal SCC [37]. Our literature review yielded only two investigations that have been conducted on the prognostic value of MMP13 in OSCCs till date [36, 38]. The first study did not observe any association between overexpression of MMP13 and clinical outcome as well as poor survival [36]. The second study which mainly focused on oral tongue SCC found a significant role for $M M P 13$ as a prognostic marker [38]. In the current study, overexpression of $M M P 13$ protein showed significant association with advanced staging and lymph node metastasis. This observation reflects the proteolytic activity of MMP13 in degradation of the ECM and basement membrane which promotes the tumor progression and invasion in OSCC. To date, there has been no extensive study on the relationship between MMP13 protein expression and lymph node metastasis in OSCC. These findings provide further support that MMP13 is involved in OSCC invasion and metastasis. In addition, it showed association with poor prognosis and remained as an independent prognostic factor after adjusting with selected clinicopathological parameters (tumor subsites and tumor differentiation) but the prognostic value of MMP13 was attenuated after controlling with lymph node status and tumor staging. This implies that significance of using MMP13 as a prognostic marker may be more pronounced after taking into account the patient's lymph node status and tumor stage.

Taken together, the overexpression of MMP13 was identified as an independent prognostic marker for OSCC at both mRNA and protein expression levels. In addition, increased expression of MMP13 protein in ODLs and OSCC as compared to normal oral mucosa and its correlation with advanced stage and lymph node metastasis of OSCC provide further evidence for its role in genesis and progression of OSCC. Further investigations regarding the interaction of 


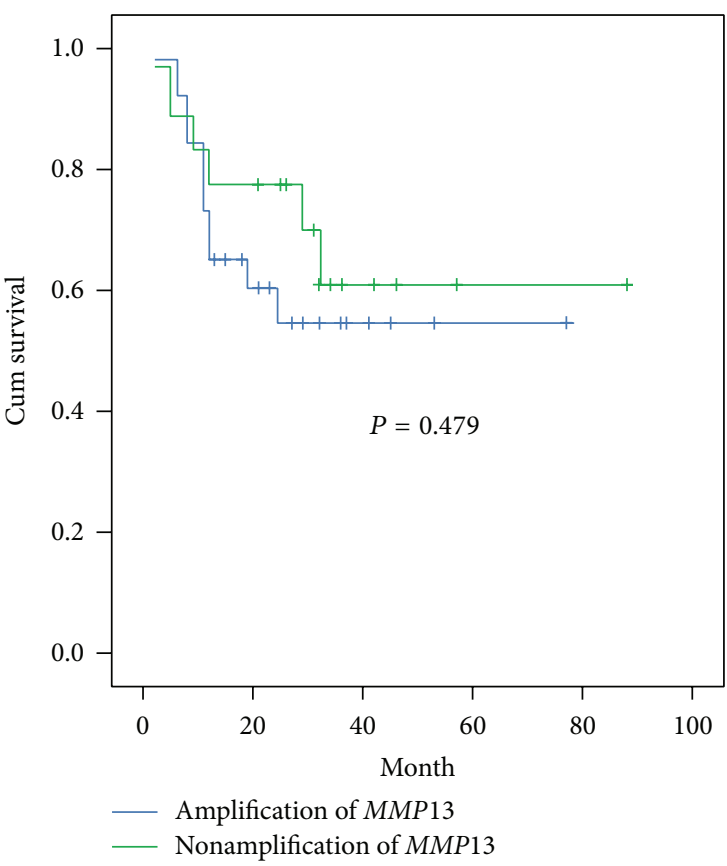

(a)

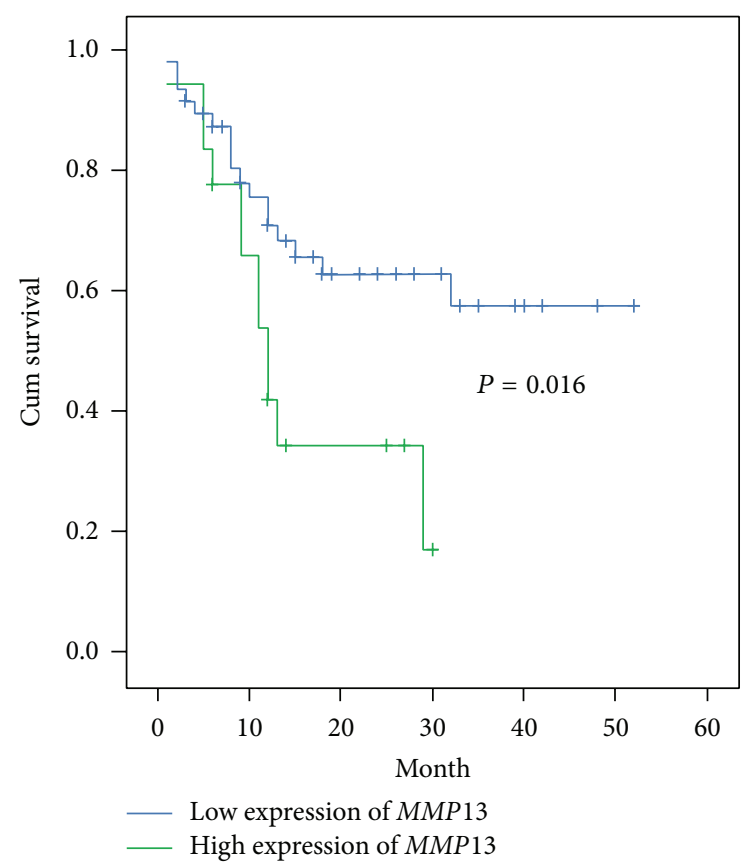

(b)

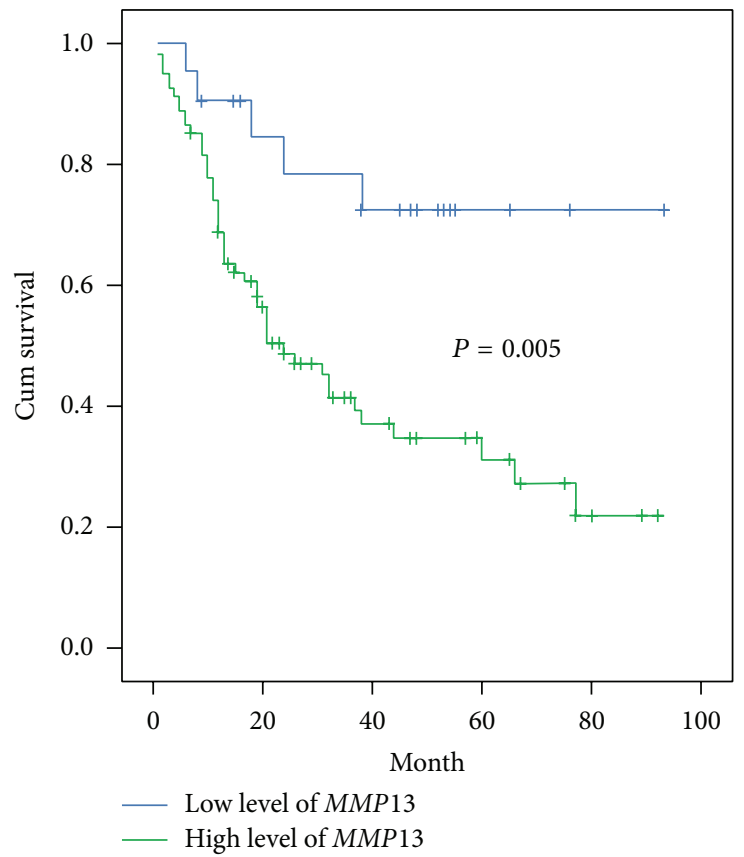

(c)

FIGURE 5: Overall survival curves were analyzed according to MMP13 copy number (a), mRNA expression (b), and protein expression (c) using Kaplan-Meier estimate with log rank test.

MMP13 with other potential genes or environmental risk factors would shed light on the complex role of this gene in pathogenesis of OSCC.

\section{Conflict of Interests}

The authors declare no conflict of interests for this research.

\section{Authors' Contribution}

Vui King Vincent-Chong conducted the experimental works and drafted the main paper. Anand Ramanathan and Thomas George Kallarakkal graded the immunostaining based on the semiquantitative scoring system. Ming Yhong Siow, Lee Peng Karen-Ng, Iman Salahshourifar, Goot Heah Khor, YiHsin Yang, Sok Ching Cheong, and Rosnah Binti Zain have 
made contributions in the conception of paper framework, interpretation of data, and critically revising the paper. Zainal Ariff Abdul Rahman, Siti Mazlipah Ismail, Narayanan Prepageran, Wan Mahadzir Wan Mustafa, Mannil Thomas Abraham, and Keng Kiong Tay contributed towards clinical data and specimens' acquisition. Rosnah Binti Zain, Anand Ramanathan, and Thomas George Kallarakkal have provided pathological expertise in samples' acquisition and selection in this study. All authors have read and approved the final paper content.

\section{Acknowledgments}

This study was supported by the High Impact Research MoE Grant UM.C/625/1/HIR/MoE/DENT/08. The authors acknowledged the Oral Cancer Research and Coordinating Centre (OCRCC), University of Malaya (UM), for providing tissue and data from the Malaysian Oral Cancer Database \& Tissue Bank System (MOCDTBS). The authors also thanked the clinicians and pathologists from Ministry of Health Malaysia for their technical expertise.

\section{References}

[1] B. W. Neville and T. A. Day, "Oral cancer and precancerous lesions," CA: A Cancer Journal for Clinicians, vol. 52, no. 4, pp. 195-215, 2002.

[2] A. Jemal, F. Bray, M. M. Center, J. Ferlay, E. Ward, and D. Forman, "Global cancer statistics," CA: A Cancer Journal for Clinicians, vol. 61, no. 2, pp. 69-90, 2011.

[3] C. R. Leemans, B. J. Braakhuis, and R. H. Brakenhoff, "The molecular biology of head and neck cancer," Nature Reviews Cancer, vol. 11, no. 1, pp. 9-22, 2011.

[4] S. Silvermam Jr., "Demographics and occurrence of oral and pharyngeal cancers. The outcomes, the trends, the challenge," Journal of the American Dental Association, vol. 132, pp. 7S-11S, 2001.

[5] D. Chin, G. M. Boyle, R. M. Williams et al., "Novel markers for poor prognosis in head and neck cancer," International Journal of Cancer, vol. 113, no. 5, pp. 789-797, 2005.

[6] F. M. F. I. Daniel, R. R. Hoffmann, M. M. Campos, and L. S. Yurgel, "Main molecular markers of oral squamous cell carcinoma," Applied Cancer Research, vol. 30, pp. 279-288, 2010.

[7] V. K. Vincent-Chong, A. Anwar, L. P. Karen-Ng et al., "Genome wide analysis of chromosomal alterations in oral squamous cell carcinomas revealed over expression of MGAM and ADAM9," PLoS ONE, vol. 8, no. 2, Article ID e54705, 2013.

[8] P. Vihinen and V.-M. Kähäri, "Matrix metalloproteinases in cancer: prognostic markers and therapeutic targets," International Journal of Cancer, vol. 99, no. 2, pp. 157-166, 2002.

[9] W. C. Scurry Jr. and B. C. Stack Jr., "Role of metalloproteins in the clinical management of head and neck squamous cell carcinoma," Head \& Neck, vol. 29, no. 12, pp. 1144-1155, 2007.

[10] A. M. Pendás, J. A. Uría, M. G. Jiménez, M. Balbín, J. P. Freije, and C. López-Otín, "An overview of collagenase-3 expression in malignant tumors and analysis of its potential value as a target in antitumor therapies," Clinica Chimica Acta, vol. 291, no. 2, pp. 137-155, 2000.

[11] N. Culhaci, K. Metin, E. Copcu, and E. Dikicioglu, "Elevated expression of MMP-13 and TIMP-1 in head and neck squamous cell carcinomas may reflect increased tumor invasiveness," $B M C$ Cancer, vol. 4, article 42, 2004.

[12] N. Johansson, K. Airola, R. Grénman, A.-L. Kariniemi, U. Saaríalho-Kere, and V.-M. Kähäri, "Expression of collagenase-3 (matrix metalloproteinase-13) in squamous cell carcinomas of the head and neck," The American Journal of Pathology, vol. 151, no. 2, pp. 499-508, 1997.

[13] M. Luukkaa, P. Vihinen, P. Kronqvist et al., "Association between high collagenase- 3 expression levels and poor prognosis in patients with head and neck cancer," Head and Neck, vol. 28, no. 3, pp. 225-234, 2006.

[14] N. Johansson, M. Vaalamo, S. Grénman et al., "Collagenase-3 (MMP-13) is expressed by tumor cells in invasive vulvar squamous cell carcinomas," The American Journal of Pathology, vol. 154, no. 2, pp. 469-480, 1999.

[15] T. Krecicki, M. Fraczek, M. Jelen, M. Podhorska, T. Szkudlarek, and T. Zatonski, "Expression of collagenase-1 (MMP-1), collagenase-3 (MMP-13) and tissue inhibitor of matrix metalloproteinase-1 (TIMP-1) in laryngeal squamous cell carcinomas," European Archives of Oto-Rhino-Laryngology, vol. 260, no. 9, pp. 494-497, 2003.

[16] Z. D. Gu, J. Y. Li, M. Li, J. Gu, and X. T. Shi, "Matrix metalloproteinases expression correlates with survival in patients with esophageal squamous cell carcinoma," The American Journal of Gastroenterology, vol. 100, pp. 1835-1843, 2005.

[17] J. M. del Casar Lizcano, F. V. Piñeiro, L. O. G. Sánchez et al., "Expression and clinical significance of collagenase-3 (MMP-13) in gastric cancer," Gastroenterologia y Hepatologia, vol. 26, no. 1, pp. 1-7, 2003.

[18] K. Airola, T. Karonen, M. Vaalamo et al., "Expression of collagenases- 1 and -3 and their inhibitors TIMP- 1 and -3 correlates with the level of invasion in malignant melanomas," British Journal of Cancer, vol. 80, no. 5-6, pp. 733-743, 1999.

[19] P. J. Bostrom, L. Ravanti, N. Reunanen et al., "Expression of collagenase-3 (matrix metalloproteinase-13) in transitional-cell carcinoma of the urinary bladder," International Journal of Cancer, vol. 88, no. 3, pp. 417-423, 2000.

[20] J. A. Uría, M. Balbín, J. M. López et al., "Collagenase-3 (MMP13) expression in chondrosarcoma cells and its regulation by basic fibroblast growth factor," American Journal of Pathology, vol. 153, no. 1, pp. 91-101, 1998.

[21] E. Roeb, M. Arndt, B. Jansen, V. Schumpelick, and S. Matern, "Simultaneous determination of matrix metalloproteinase (MMP)-7, MMP-1, -3, and -13 gene expression by multiplex PCR in colorectal carcinomas," International Journal of Colorectal Disease, vol. 19, no. 6, pp. 518-524, 2004.

[22] J. M. P. Freije, I. Díez-Itza, M. Balbín et al., "Molecular cloning and expression of collagenase-3, a novel human matrix metalloproteinase produced by breast carcinomas," The Journal of Biological Chemistry, vol. 269, no. 24, pp. 16766-16773, 1994.

[23] J.-R. Wang, X.-H. Li, X.-J. Gao et al., "Expression of MMP-13 is associated with invasion and metastasis of papillary thyroid carcinoma," European Review for Medical and Pharmacological Sciences, vol. 17, no. 4, pp. 427-435, 2013.

[24] M. Cazorla, L. Hernandez, A. Nadal et al., "Collagenase-3 expression is associated with advanced local invasion in human squamous cell carcinomas of the larynx," The Journal of Pathology, vol. 186, pp. 144-150, 1998.

[25] A. A. Dünne, R. Mandic, S. Falkenberg, C. V. Dalchow, A. M. Sesterhenn, and J. A. Werner, "RT-PCR expression profiling of matrix metalloproteinases and their specific inhibitors in cell lines and fresh biopsies of squamous cell carcinomas of the head and neck," In Vivo, vol. 19, no. 5, pp. 943-948, 2005. 
[26] P. O-Charoenrat, P. H. Rhys-Evans, and S. A. Eccles, "Expression of matrix metalloproteinases and their inhibitors correlates with invasion and metastasis in squamous cell carcinoma of the head and neck," Archives of Otolaryngology_Head and Neck Surgery, vol. 127, no. 7, pp. 813-820, 2001.

[27] C. H. Chung, J. S. Parker, G. Karaca et al., "Molecular classification of head and neck squamous cell carcinomas using patterns of gene expression," Cancer Cell, vol. 5, no. 5, pp. 489-500, 2004.

[28] R. B. Zain, V. Athirajan, W. M. Ghani et al., "An oral cancer biobank initiative: a platform for multidisciplinary research in a developing country," Cell \& Tissue Banking, vol. 14, no. 1, pp. 45-52, 2013.

[29] L. H. Sobin, M. K. Gospodarowicz, and C. Wittekind, TNM Classification of Malignant Tumours, John Wiley \& Sons, New York, NY, USA, 2011.

[30] K. J. Livak and T. D. Schmittgen, "Analysis of relative gene expression data using real-time quantitative PCR and the $2^{-\triangle \triangle C_{T}}$ method," Methods, vol. 25, no. 4, pp. 402-408, 2001.

[31] B. D'haene, J. Vandesompele, and J. Hellemans, “Accurate and objective copy number profiling using real-time quantitative PCR," Methods, vol. 50, no. 4, pp. 262-270, 2010.

[32] J. Kononen, L. Bubendorf, A. Kallioniemi et al., "Tissue microarrays for high-throughput molecular profiling of tumor specimens," Nature Medicine, vol. 4, no. 7, pp. 844-847, 1998.

[33] N. Bektas, E. Noetzel, J. Veeck et al., "The ubiquitin-like molecule interferon-stimulated gene 15 (ISG15) is a potential prognostic marker in human breast cancer," Breast Cancer Research, vol. 10, no. 4, article R58, 2008.

[34] C.-L. Liao, M.-Y. Lee, Y.-S. Tyan et al., "Progesterone receptor does not improve the performance and test effectiveness of the conventional 3-marker panel, consisting of estrogen receptor, vimentin and carcinoembryonic antigen in distinguishing between primary endocervical and endometrial adenocarcinomas in a tissue microarray extension study," Journal of Translational Medicine, vol. 7, article 37, 2009.

[35] I. Zlobec, R. Steele, L. Terracciano, J. R. Jass, and A. Lugli, "Selecting immunohistochemical cut-off scores for novel biomarkers of progression and survival in colorectal cancer," Journal of Clinical Pathology, vol. 60, no. 10, pp. 1112-1116, 2007.

[36] W.-C. Chiang, Y.-K. Wong, S.-C. Lin, K.-W. Chang, and C.J. Liu, "Increase of MMP-13 expression in multi-stage oral carcinogenesis and epigallocatechin-3-gallate suppress MMP-13 expression," Oral Diseases, vol. 12, no. 1, pp. 27-33, 2006.

[37] T. Etoh, H. Inoue, Y. Yoshikawa, G. F. Barnard, S. Kitano, and M. Mori, "Increased expression of collagenase-3 (MMP-13) and MT1-MMP in oesophageal cancer is related to cancer aggressiveness," Gut, vol. 47, no. 1, pp. 50-56, 2000.

[38] L. K. Mäkinen, V. Häyry, T. Atula et al., "Prognostic significance of matrix metalloproteinase-2, $-8,-9$, and -13 in oral tongue cancer," Journal of Oral Pathology \& Medicine, vol. 41, no. 5, pp. 394-399, 2012.

[39] D. G. Albertson, "Gene amplification in cancer," Trends in Genetics, vol. 22, no. 8, pp. 447-455, 2006.

[40] S. M. Hewitt, J. Dear, and R. A. Star, "Discovery of protein biomarkers for renal diseases," Journal of the American Society of Nephrology, vol. 15, no. 7, pp. 1677-1689, 2004.

[41] S. Yamamoto, M. Yamamoto-Ibusuki, Y. Yamamoto, S. Fujiwara, and $\mathrm{H}$. Iwase, "A comprehensive analysis of Aurora A; transcript levels are the most reliable in association with proliferation and prognosis in breast cancer," BMC Cancer, vol. 13, article 217, 2013. 


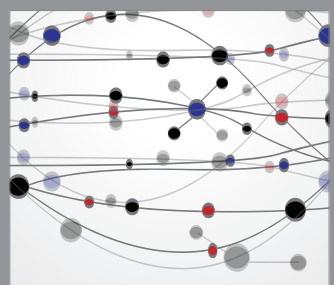

The Scientific World Journal
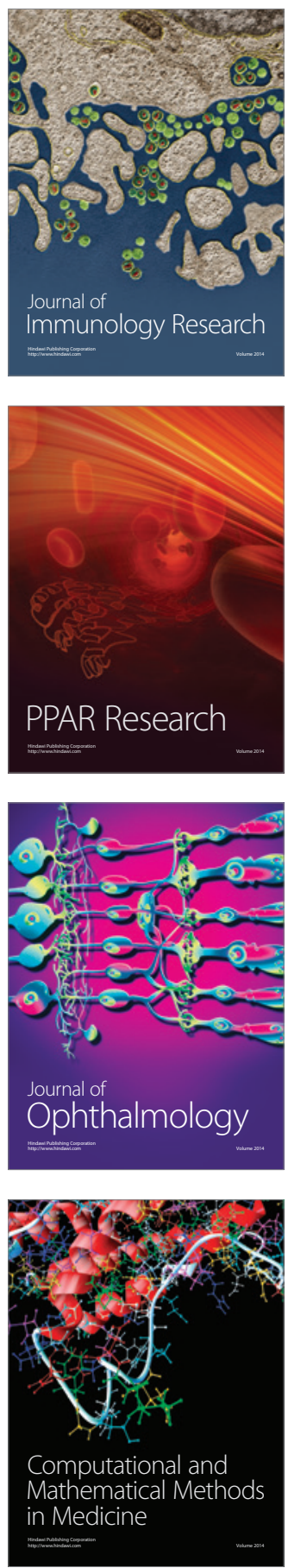

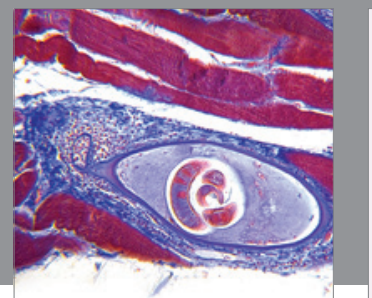

Gastroenterology

Research and Practice
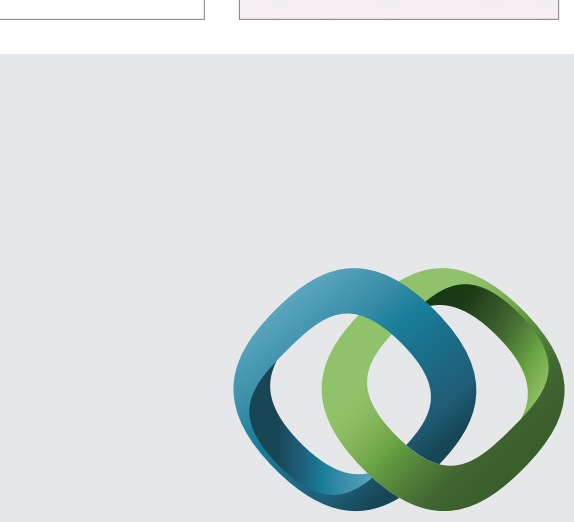

\section{Hindawi}

Submit your manuscripts at

http://www.hindawi.com
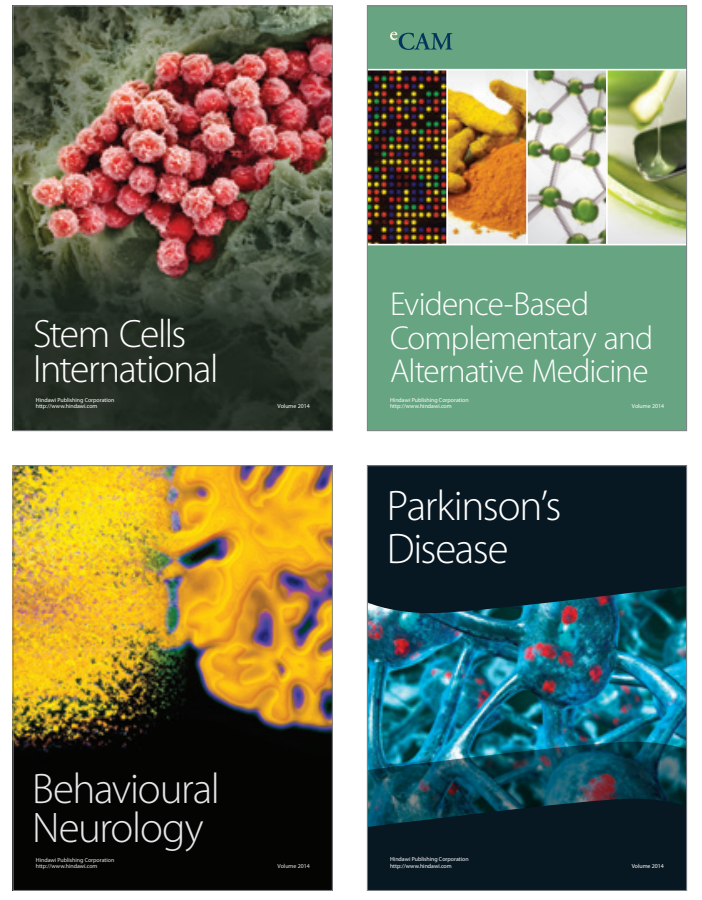
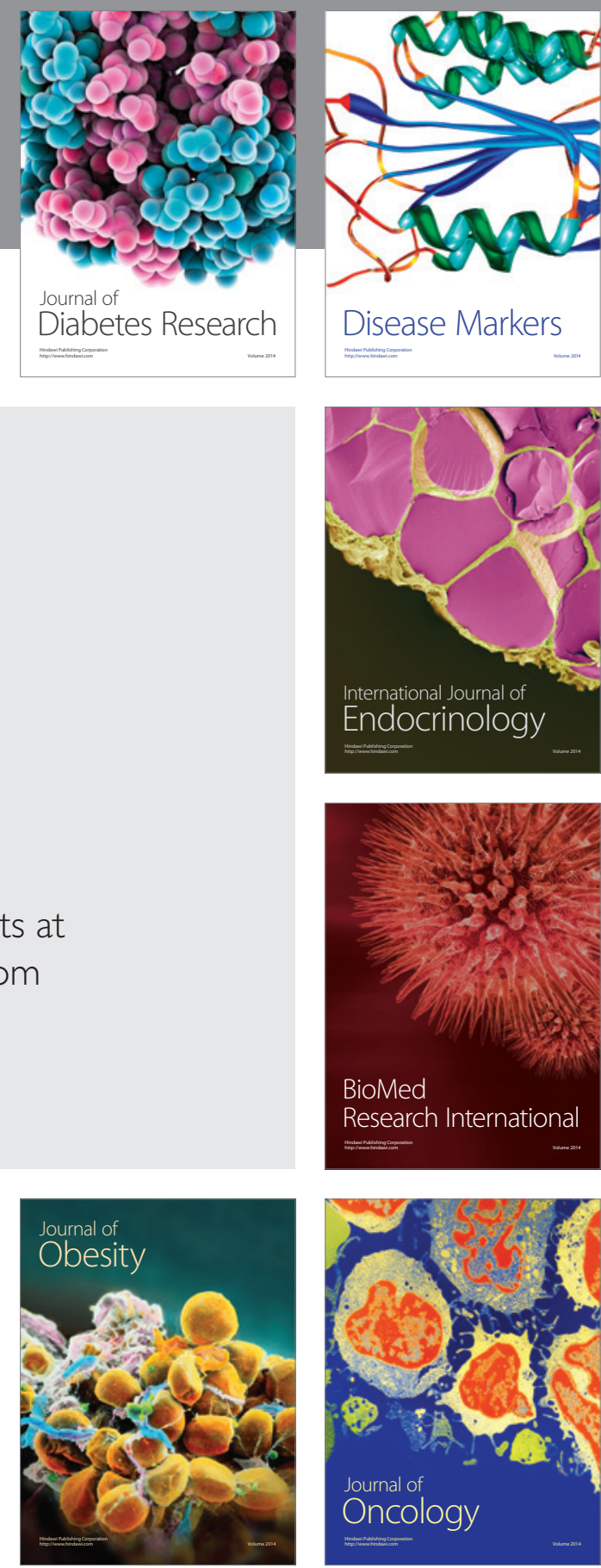

Disease Markers
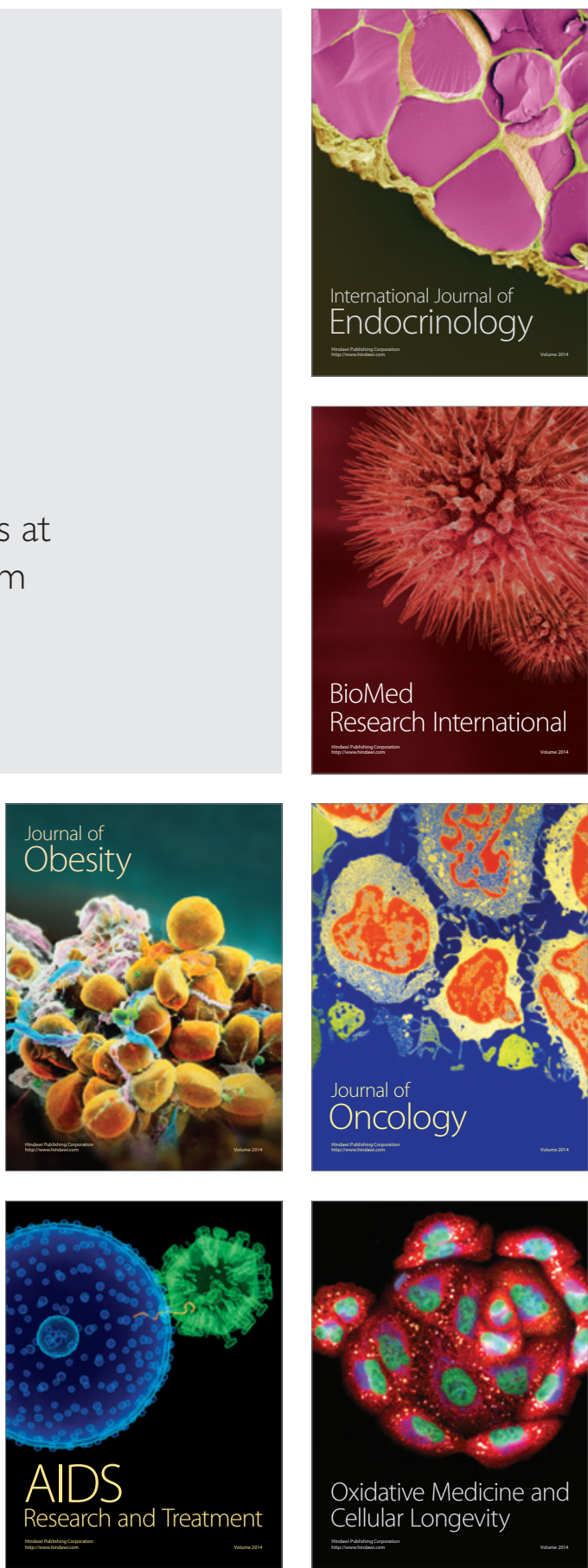